Available online on 15.01 .2020 at http://jddtonline.info
Open Access to Pharmaceutical and Medical Research
unrestricted non-commercial use, provided the original work is properly cited

Open? Access

Review Article

\title{
Solid Dispersion: Solubility Enhancement Technique of Poorly Water Soluble Drug
}

\section{Ikram*, Kapil Kumar}

Global Institute of Pharmacy Education and Research, Kashipur, Uttarakhand, India

\begin{abstract}
Solid dispersion is a technique which is widely and successfully applied to improve the solubility, dissolution rates and consequently the bioavailability of poorly soluble drugs. Dispersion of one or more active ingredients (hydrophobic) is done with an inert carrier (hydrophilic) at solid-state prepared by fusion method, solvent, and melting solvent method. In this review article, we have focused on the methods of preparation, advantages, disadvantages and characterization of the solid dispersions.
\end{abstract}

Keywords: Solid dispersion; dissolution; solubility.

Article Info: Received 21 Oct 2019; $\quad$ Review Completed 28 Dec 2019; $\quad$ Accepted 03 Jan2019; Available online 15 Jan 2020

Cite this article as:

Ikram, Kumar K, Solid Dispersion: Solubility Enhancement Technique of Poorly Water Soluble Drug, Journal of Drug Delivery and Therapeutics. 2020; 10(1):173-177 http://dx.doi.org/10.22270/jddt.v10i1.3925

*Address for Correspondence:

Ikram, Global Institute of Pharmacy Education and Research, Kashipur, Uttarakhand, India

\section{INTRODUCTION:}

Solid dispersion is defined as a group of solid products which should contain at least two different components, like a hydrophilic matrix and a hydrophobic drug. Hydrophilic matrix can be crystalline or amorphous. The first drug whose rate and extent of absorption was significantly enhanced using solid dispersion was sulfathiazole in which eutectic mixture of sulfathiazole with urea as the inert carrier was formed. Lyophilization is a molecular mixing technique where the drug and carrier were co-dissolved in cyclohexanol, frozen and then sublimed under vacuum to obtain a lyophilized molecular dispersion [1].

Solubility is not to be confused with the ability to dissolve or liquefy a substance, since these processes may occur not only because of a chemical reaction. Solubility does not depend on particle size or other kinetic factors; given enough time, even large particles will eventually dissolve $[2$, 3].
Several factors such as complicated preparation method, low reproducibility of physicochemical properties, difficulty of formulation development and scale-up and physical instability for solid dispersion make it difficult to apply the systems to solid dispersion dosage forms. Especially in order to maintain a supersaturation level of drug for an extended time, re-crystallization of drug must be prevented during its release from dosage form 4 .

After administration of a drug orally, it firstly dissolves in gastric media and then permeates the membranes of GI tract to reach into the blood. Therefore, a drug with poor aqueous solubility will exhibit dissolution rate limited absorption. $35-40 \%$ of newer drugs suffer from poor aqueous solubility5,6. 


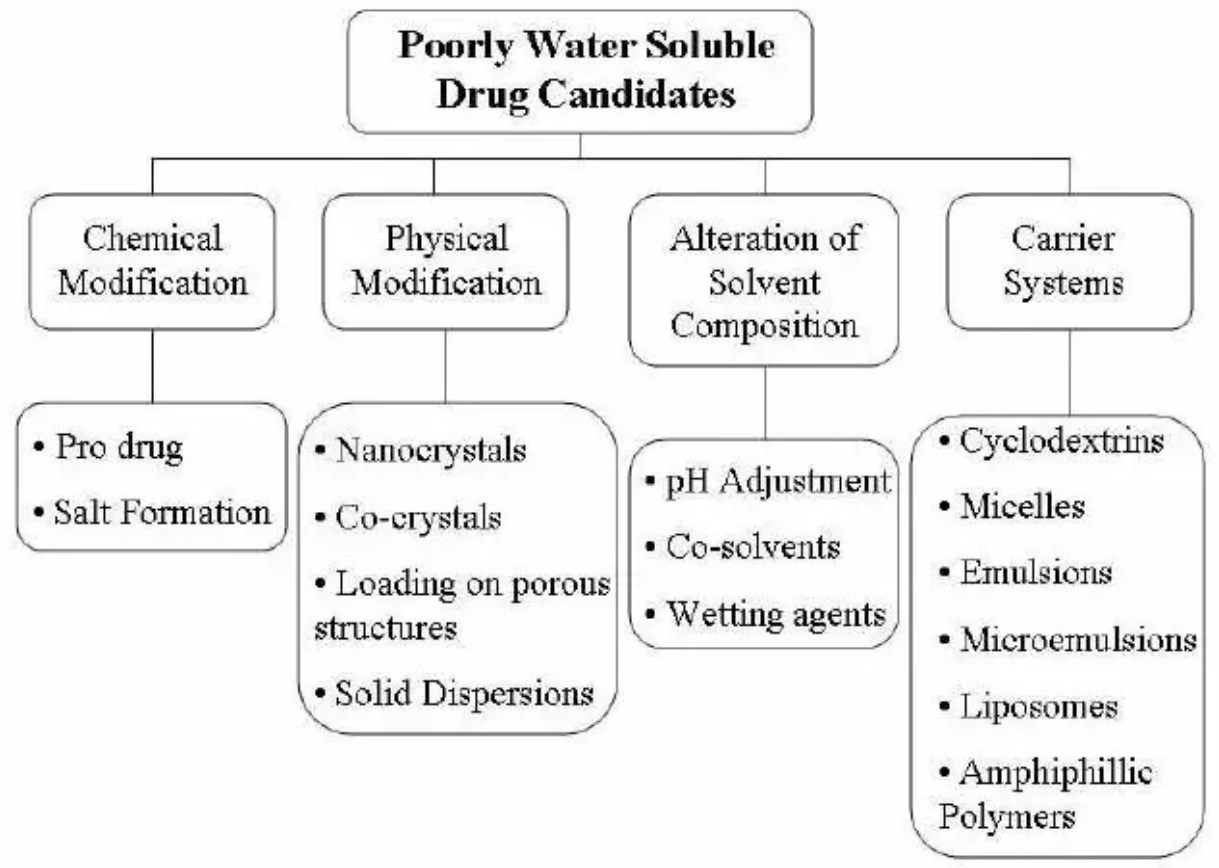

Figure 1. Approaches to Increase solubility/ Dissolution

\section{ADVANTAGES OF SOLID DISPERSION}

1. Improving drug bioavailability by changing water solubility which is possible only by solid dispersion?.

2. Increase in dissolution rate \& extent of absorption and reduction in Pre systemic metabolism.

3. Transformation of liquid form to solid form.

4. It is more efficient than particle size reduction technique [8]

\section{DISADVANTAGES OF SOLID DISPERSION}

1. Major disadvantage is their instability. They show changes in crystallinity and a decrease in dissolution rate with ageing.

2. Temperature and moisture have more deteriorating effect on solid dispersions than on physical mixtures.

3. Difficulty in handling because of tackiness [9,10].

\section{METHODS OF PREPARATION OF SOLID DISPERSIONS:}

\section{Solid Dispersion}

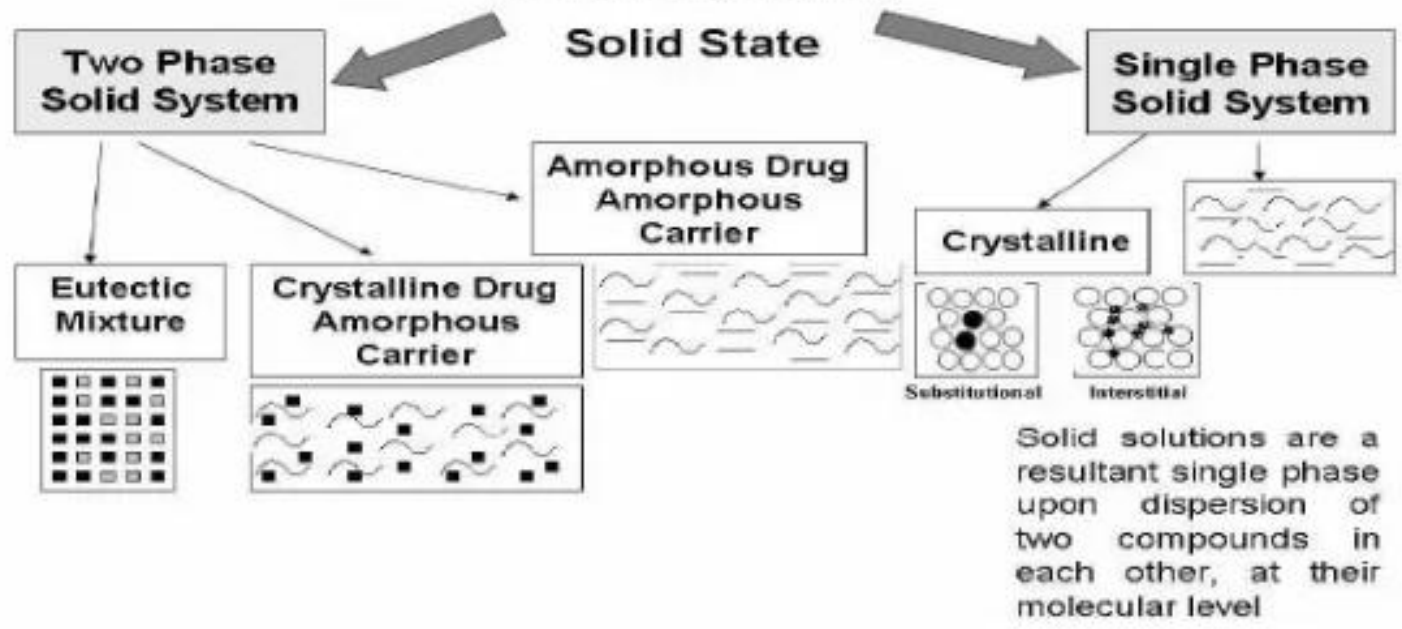

Figure 2. Solid State Solid Dispersions 


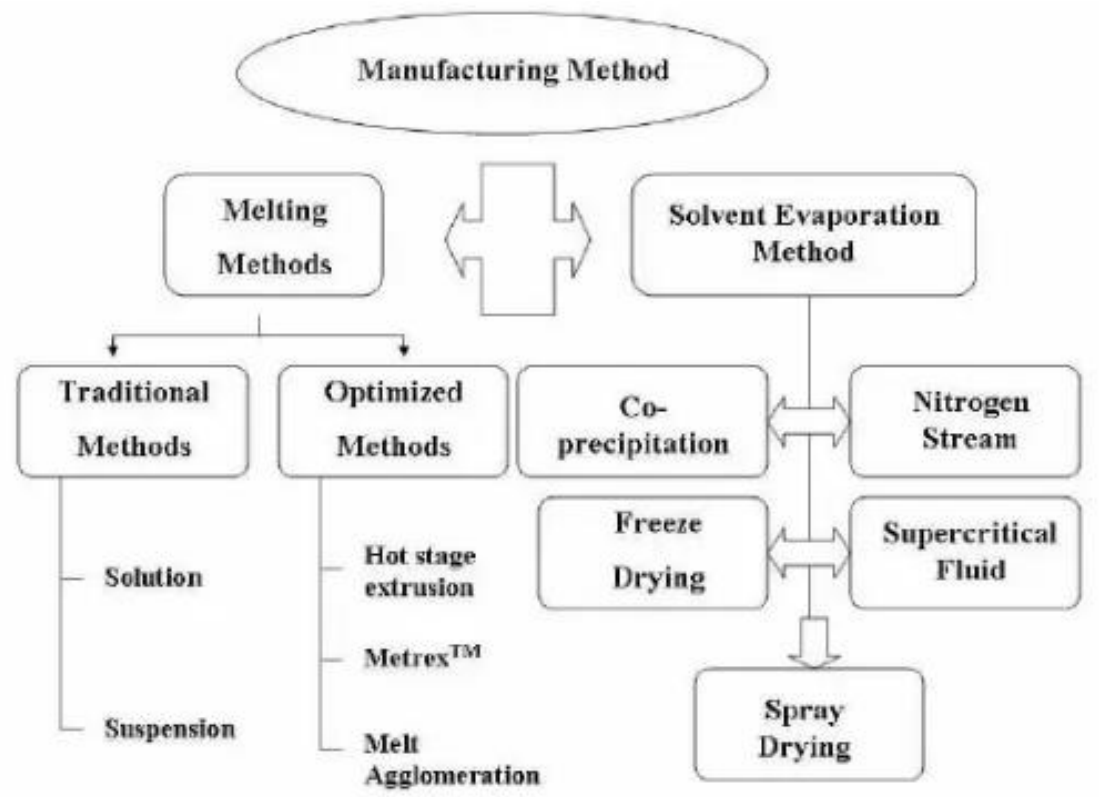

Figure 3. Methods of preparation of Solid Dispersion

Various methods used for preparation of solid dispersion system. These methods are given below.

1. Melting solvent method: This method is prepared by physical mixture of a drug and a water soluble carrier and heating it directly until it is melted. Final solid mass is crushed and sieved and then it passed with other modification procedures [11,12].

2. Solvent evaporation method: In this type of method dissolve the drug and polymeric carrier in a common solvent, such as ethanol, chloroform, mixture of ethanol and dichloromethane, resulting films are pulverized and milled [13-17],

3. Hot melt extrusion method: In this method extruder is utilized for intense mixing of components. Physical mixture of both the drug and carrier is introduced into the hopper then passed through screw and finally it is extruded from the die [18].

4. Melt agglomeration Process: This technique has been used to prepare solid dispersion wherein the binder acts as a carrier. Solid dispersion are prepared by heating binder, drug \& excipient to a temperature above the melting point of the binder or by spraying a dispersion of drug in molten binder on the heated excipient by using shear mixer [19-21].

5. Lyophilization: it is a phenomenon of transfer of heat and mass from and to the product. It's an alternative method to solvent evaporation in which molecular mixture technique is used[22].

\section{EVALUATION PARAMETERS OF SOLID DISPERSION:}

Various methods to evaluate the solid dispersion are as follows: Drug -carrier miscibility

- Hot stage microscopy

- Differential scanning calorimetry - Helps to determine that the treated drug melting is similar to the original form of the drug.
- Powder X-ray diffraction - The intensity peaks shows the crystal lattice of the treated drug. Low and high intensity peaks are evaluated for the crystallization index.

- Spectroscopic methods like Raman spectroscopy, FT-IR spectroscopy - the functional groups of the treated drug produces similar peaks as that of the original drug form which helps to determine that the no changes in the functional structure of the drug moiety 22 .

\section{Physical Structure}

- Scanning electron microscopy - SEM shows the surface morphology of the drug particles and to evaluate them with the treated drug23.

- Surface area analysis - The surface area is directly proportional to the solubility of the drug.

- Dynamic vapour sorption

- Inverse gas chromatograph

- Atomic force microscopy

- Raman microscopy

Amorphous content

- Polarised light optical microscopy

- Hot stage microscopy

- Humidity stage microscopy

- DSC (MTDSC)

- Powder X-ray diffraction ${ }^{24}$

Stability

- Humidity studies

- Isothermal Calorimetry

- DSC (TG, Temperature recrystallization)

- Saturated solubility studies

Dissolution enhancement

- Dissolution 
- Intrinsic dissolution

- Dynamic solubility

- Dissolution in bio-relevant media25

Applications of solid Dispersion:

The solid dispersion technique may have numerous pharmaceutical applications, which are:

1. To stabilize unstable drugs and protect against decomposition by processes such as hydrolysis, oxidation, racemization, photo oxidation etc ${ }^{26}$.

2. To reduce side effects of certain drugs:- A third factor that affects the rate of dissolving is the size of solute particles. For a given amount of solute, smaller particles have greater surface area. With greater surface area, there can be more contact between particles of solute and solvent 27 .

3. Masking of unpleasant taste and smell of drugs:- Taste masking has always been the integral part of formulation especially for pediatric formulations. During almost last three decades advanced novel formulation techniques have been utilized to improve the aesthetics of the final products.

4. To avoid undesirable incompatibility.

5. To obtain a homogeneous distribution of a small amount of drug in solid state :- Solubility is the property of a solid, liquid, or gaseous chemical substance called solute to dissolve in a solid, liquid, or gaseous solvent to form a homogeneous solution of the solute in the solvent. The solubility of a substance fundamentally depends on the solvent used as well as on temperature and pressure.
6. To dispense liquid or gaseous compounds 28 .

7. To formulate a fast release priming dose in a sustained release dosage form.

8. To formulate sustained release preparation of soluble drugs by dispersing the drug in poorly soluble or insolub to formulate sustained release preparation of soluble drugs by dispersing the drug in poorly soluble or insoluble carrier ${ }^{29}$.

9. To enhance the absorption of drug.

10. To reduce side effects:-

(A). The binding ability of drugs for example to the erythrocyte membrane is decreased by making its inclusion complex.

(B). The damage to the stomach mucous membranes by certain non-steroidal anti-inflammatory drugs can be reduced by administration as an inclusion compound ${ }^{30}$.

\section{Challenging future for Solid Dispersion Technique:}

A. Inability to scale bench top formulations to manufacturing sized batches,

B. Difficulty to control physiochemical properties,

C. Difficulty in delivering solid dispersion formulations as tablet or capsule dosage forms and

D. Physical and chemical instability of the drug and/or the formulation [31].

\section{Commercial Solid Dispersion Products:}

List of products available in the market [6]

\section{Brand name}

\begin{tabular}{ll}
\hline Gris-PEG & Pedinol Pharmacal Inc. \\
Cesamet & Valeant Pharmaceuticals \\
Kaletra & Abbott \\
Sporanox & Janssen Pharmaceutica \\
Intelence & Tibotec \\
Certican & Novartis \\
Isoptin SR-E & Abbott \\
Nivadil & Fujisawa Pharmaceutical Co., Ltd \\
Prograf & Fujisawa Pharmaceutical Co., Ltd \\
Rezulin & Developed by Sankyo, manufactured by \\
& Parke-Davis division of Warner-Lambert
\end{tabular}

Drug

Carrier

$\begin{array}{ll}\text { Griseofulvin } & \text { PEG6000 } \\ \text { Nabilone } & \text { PVP } \\ \text { Lopinavir, ritonavir } & \text { PVPVA } \\ \text { Itraconazole } & \text { HPMC } \\ \text { Etravirin } & \text { HPMC } \\ \text { Everolimus } & \text { HPMC } \\ \text { Verapamil } & \text { HPC/HPMC } \\ \text { Nivaldipine } & \text { HPMC } \\ \text { Tacrolimus } & \text { HPMC } \\ \text { Troglitazone } & \text { PVP }\end{array}$

\section{CONCLUSION}

Increasing the Bioavailability of a poorly soluble drug is a challenging aspect of drug development.on the basis of back literature we have concluding solid dispersion is the promisable technique increment of solubility and bioavailability of water insoluble (BCS Class II). Because of the poor aqueous solubility the drug possesses dissolution problems due to which the in vivo absorption of the drug is reduced and thus the bioavailability is reduced, making the drug inappropriate for oral consumption and therefore solubility enhancement become necessary for such drug candidate. Solid dispersion is a most simple and efficient technique for increasing the aqueous solubility of a drug. Solid dispersion systems have been realized as extremely useful tool in improving the dissolution properties of poorly water-soluble drugs based on the observed entrapment rates and pesticide loadings, the processes for preparing the solid dispersions were optimized.

\section{REFERENCES}

1. Abdul-Fattah AM, Bhargava HN. Preparation and in vitro evaluation of solid dispersions ofhalofantrine. Int J Pharm. 2002; 235:17-33.PubMed DOI: 10.1016/S03785173(01)00941-3(11)

2. Adel M. Aly, M.Semreen, and Mazen K. Qato. Superdisintegrants for Solid dispersion. Pharmaceutical Techlology January 2005, 68-78.

3. A. Martin, Solubility and Distribution Phenomena, Physical Pharmacy and Pharmaceutical Sciences, Lippincott Williams and Wilkins, 6th edition, 2011

4. Angus Forster, John Hempenstall, Thomas Rades. Selection of Suitable Drug and ExcipientsCandidates to Prepare Glass Solutions by Melt Extrusion for Immediate Release Oral Formulations. Pharmaceutical Technology Europe. 01 October 2002 (6) 
5. Arunachalam A, Karthikeyan M, konam K, Prasad $\mathrm{PH}$ Sethuraman S and Ashutoshkumar S: Solid Dispersion : A Review. Current Pharmaceutical Research 2010; (1): 82-90

6. A.T.M. Serajuddin; Solid Dispersion of Poorly Water-Soluble Drugs: Early Promises,A.T.M. Serajuddin; Solid Dispersion of Poorly Water-Soluble Drugs: Early Promises,

7. Aungst, B. J., N. H. Nguyen, N. J. Rogers, S. M. Rowe, M. A. Hussain, S. J. White and L.Shum,1977. Ampiphilic vehicles improve the oral bioavailability of a poorly soluble HIV proteaseinhibitor at high doses. Int J Pharm156:79-88 (98)

8. Billa, N., Yuen, K., 2000. Formulation variables affecting drug release from xanthan gum matrices at laboratory scale and pilot scale. AAPS Pharm Sci Tech. 1(4), article 30.

9. Cheow W, Hadinoto K. Self-assembled amorphous drugpolyelec-trolyte nanoparticle complex with enhanced dissolution rate andsaturation solubility. J Colloid Interface Sci 2012;367:518-26.

10. Damian F, Blaton N, Kinget R and Mooter G Van den. Physical stability of solid dispersions ofthe antiviral agent UC-781 with PEG 6000, Gelucire 44/14 and PVP K3. Int. J. Pharm. 244, 2002,87-98 (53).

11. Mahmoud A. Younis. Solid dispersion technology, a contemporary overview on a well established technique. Universal Journal of Pharmaceutical Research. 2017; 2(3): 1519.

12. Dixit et al; A review-solid dispersion, 2014; World Journal of Pharmacy and Pharmaceutical Sciences; 3(9); 238-257.

13. Karanath $\mathrm{H}$, Shenoy VS and Murthy RR: Industrially Feasible Alternative Approaches in the AAPS. Pharmaceutical Sciences and Technology 2006; 7: 1-9.

14. Kim KT, Lee JY, Lee MY, Song CK, Choi J and Kim DD: Solid Dispersions as a Drug Delivery System. Journal of Pharmaceutical Investigation 2011; 41(3): 125-142

15. Kramer, J., Grady, L. T. and Gajendran, J., 2005. Historical development of dissolution testing, in; Jennifer, D. and Johannes, K., Pharmaceutical dissolution testing, Taylor and Francis, 1-4.

16. Kumar S, Shenoy VS and Sharma PK: Solid dispersion: Pharmaceutical Technology for the improvement of various characteristics of active pharmaceutical ingredients. African journal of basic and applied sciences 2011;3(4): 116-125

17. Pouton, C. W., Formulation of poorly water-soluble drugs for oral administration: physico-chemical and physiological issues and the lipid formulation classification system Eur. J.Pharm. Sci., 29: 278, 2006. (14).

18. Akhter S, Hossen MS, Salahuddin M, Sunny MA, Sathi FA, Islam MS. In vitro dissolution study of glimepiride from binary and ternary solid dispersion formulation. Universal Journal of Pharmaceutical Research 2019; 4(5):7-12.
19. Sebhatu T, Angberg M and Ahlneck C (1994). Assessment of the degree of disorder in crys-talline solids by isothermal microcalorimetry. Int. J. Pharm., 104: 135-144. (94)

20. Smithey PGD, Taylor LS. Amorphous solid dispersions: an enablingformulation technology for oral delivery of poorly water solubledrugs. AAPS Newsmag 2013;16:11-14.

21. Sujja-Areevath., Munday, D.L., Cox, P.J., Khan, K.A., 1998. Relationship between swelling, erosion and drug release in hydrophilic natural gum mini-matrix formulations. Eur. J. Pharm. Sci., 6, 207-217.

22. Usman Mohammed Jajere, Achadu AE. Fabrication and characterization of ezetimibe solid dispersion for solubility enhancement. Universal Journal of Pharmaceutical Research. 2017; 2(1): 12-16.

23. Thakur et al; A review on solid dispersion; World Journal of Pharmacy and Pharmaceutical Sciences; 2014; 3(9); 173-187.

24. Kumar A, Kumar K. Solid dispersion-strategy to enhance solubility and dissolution of poorly water soluble drugs. Universal Journal of Pharmaceutical Research. 2017; 2(5): 54 59.

25. VermaS ,Rawat A, Kaul M and Saini S: Solid Dispersion: A Strategy For Solubility Enhancement . International Journal of Pharmacy \& Technology2011; 3(2): 1062-1099.

26. Won DH. Improved physicochemical characteristics of felodipine solid dispersion particles by supercritical anti solvent precipitation process. Int J Pharm. 2005; 301: 199-208.

27. Yadav B, Tanwar YS. Development, characterization and in vitro evaluation of flurbiprofen solid dispersions using polyethylene glycols as carrier. J App Pharm Sci. 2016; 6 (04): 060-066.

28. Yoshihashi Y: Estimation of physical stability of amorphous solid dispersion using differential scanning calorimetry. Journal of Thermal Analysis and Calorimetric 2006; 85: 689- 692.

Youn YS. Improved intestinal delivery of salmon calcitonin by Lys18- amine specific PEGylation: Stability, permeability, pharmacokinetic behavior and in vivo hypocalcemic efficacy. J Contr Rel. 2006; 334-342.

29. Zhang $\mathrm{R}$ and Somasundaran $\mathrm{P}$. Advances in adsorption of surfactants and their mixtures atsolid/solution interfaces. Advances in colloid and interface science 123-126, 2006, 213229.(49)

30. Zhang W, Yan E, Huang Z, Wang C, Xin Y, Zhao Q, and Tong Y. Preparation and study of PPV/PVA nanofibers via electrospinning PPV precursor alcohol solution. European polymer 43,2007, 802-897. (78).

31. Md. Shahidul Islam, Rasheda Akter Lucky. Development and in vitro dissolution study of binary and ternary solid dispersions of aceclofenac. Universal Journal of Pharmaceutical Research 2019; 4(1): 29-36. 